MedieKultur | Journal of media and communication research | ISSN 1901-9726

Book Review

\title{
Steen Christiansen
}

\author{
Tarja Laine: \\ Feeling Cinema. \\ New York: Bloomsbury, 2013
}

MedieKultur 2014, 57, 226-228

Published by SMID | Society of Media researchers In Denmark | www.smid.dk The online version of this text can be found open access at www.mediekultur.dk

Tarja Laine's second book continues her interest in emotional dynamics in films and argues for a synthetic approach, drawing on both sensory and cognitive insights. Sensory theories and theories of emotional engagement consist of what is often referred to as the third wave of film theory. Yet this third wave is in no way homogenous and does not draw on the same critical foundations. On the one hand, we have a mostly phenomenological tradition that originates with Vivian Sobchack and Laura Marks and has since become established with critics and theorists like Jennifer M. Barker, Anne Rutherford, Patricia Pisters, and Barbara Kennedy. ${ }^{1}$ On the other hand, we have a (neuro)cognitive tradition that comes from David Bordwell, Noël Carroll, and later practitioners such as Carl Plantinga, Ed Tan, and Torben Grodal.

As Laine points out, there is a tendency for sensory theories to emphasize affect and sensation, while the cognitive theories emphasize emotions. Laine deliberately places herself between these two traditions, instead wishing to "approach cinematic emotions as unified states or processes that involve both affective appraisals and emotional evaluations, affect being an implicit quality of the stream of emotion." (p. 2) Through this interesting combination, Laine goes on to posit that cinematic emotions (as semi-distinct from everyday emotions) arise from the cinematic event. Laine even goes so far as to suggest that cinematic emotions may be other than human feelings, since they are operational processes within the film (p. 4). In doing so, Laine aligns herself with other recent formalist studies of affects and feelings in cinema, such as Eugenie Brinkema's The Forms of the Affects (Duke University Press, 2014) and Anne Rutherford's What Makes a Film Tick? (Peter Lang, 2011). 
The formalist approach to cinematic emotions is based on the individual film's "salient techniques", a phrase that Laine openly adopts from Bordwell and Thompson. However, Laine diverges from a purely formalist approach a la Bordwell and Thompson when she argues that a film is an agent producing emotions in its viewer. As such, films have emotional cores that are analogous to human emotional states, and it is through these states that we engage emotionally with a film, rather than through an engagement with characters or narrative. Of course, a film's emotional core might be 'about' what happens to a central character, but it need not be. An approach based on a film's emotional core is strong, since it opens up studies of both art cinema and popular cinema, being equally sensitive to both. For a field that has a tendency to divide itself strongly between either art cinema (many affect studies) or popular cinema (cognitive approaches), this is a welcome breath of fresh air. It is also refreshing to find an approach not expressly focusing on narrative or characters, but once again giving cinema back some of its aesthetic resonance.

Laine's book is centered on the emotional cores of a range of films. After her introductory chapter that mainly positions her theoretically, follow seven chapters, all focused on a specific emotion: horror, hope, trauma, anguish, shame, anger, and love, respectively. Specific intellectual and cultural histories of these emotions are provided in the opening of each chapter, following which a few analyses of individual films make up the bulk of the chapter. These readings are all strong and interesting, paying close attention to mise-en-scene, narrative, and characters, even as she endeavors to step outside of traditional readings.

For example, in her opening chapter on horror, Laine discusses The Shining and Repulsion. She employs these masterpieces of cinematic horror to refute the analytic need for character identification, sympathetic responses to characters, and evaluative, emotional responses to films as training wheels for unfamiliar situations. Rather, Laine argues, we must pay attention to the ways in which the formal elements of the film intermingle with our emotional systems (p. 27). So The Shining is scary, not because I imagine myself trapped in Overlook Hotel, but because of the tremulous opening score, the gallons of blood gushing from the elevator doors, and the Grady twins' embodiment of death as entrapment instead of release.

This line of argument reveals Laine's basic analytic approach: locate prominent scenes of a film, identify their emotional and affective qualities, relate these qualities to the film's general thematic thrust. Such an approach works well and provides startling insights at times, such as the way in which Laine finely articulates how Elephant (Gus Van Sant, 2003) embodies contempt through its use of double focalization. As we follow both the killersto-be and the victims-to-be, we are aligned as much with the killers as with the victims. While in no way arguing that the film produces sympathy for the killers, Laine points out why the film is to disturbing: because we are brought to understand the killers as much as the victims. We feel the killers' feelings of superiority, which is a deeply disturbing sensation.

In moments like these, Laine's arguments are strong, since they point to the ways in which cinema works as a way of fostering experiences that we would otherwise never have, 
nor would want to have in real life. At the same time, she avoids the dubious idea that films work as training wheels (if this were true, many films should be banned). She also steers clear of totalizing, simplistic arguments about human biology as the foundation of cinematic perception, while remaining aware of the useful work carried out in the field of embodied cognition, such as Antonio Damasio's insightful work.

And yet, maybe Laine is not as agnostic as she claims to be. Although she argues at the opening of her book that cinema's emotions are analogous to, but not identical to, human emotions, she never truly engages seriously with this idea. All the emotional cores Laine locates are human emotions for human beings. Love, anger, anguish and so forth are all recognizable emotions that we all feel. Yet, is cinema's strength not precisely, as Laine herself argues but never shows, that it can confront us with feelings beyond the human? In fact, is one of the reasons why The Shining is so terrifying not the nonhuman scales the film embodies and sets in motion? The vast timescale of the mountains in the opening shot versus the cyclical timescale of Jack having always been at Overlook Hotel? Or the infinite regress of Overlook's labyrinthine hallways, mirrored in the hedge maze and Jack's writing, making the hotel endlessly large? These encounters produce feelings beyond the human, introducing scales beyond our comprehension, and remain some of the most memorable moments of the film. More attention to the nonhuman dimension of cinema would have furthered many of the otherwise insightful discussions.

Such quibbles aside, Laine's book remains strong and contains many valuable additions to the growing body of scholarly work on cinema and emotions. The book serves both as a good introduction to the debates regarding emotions and affects in cinema, while also pushing the field further, particularly in its synthesis of two often competing traditions.

\section{Note}

1 Some might point out that both Pisters and Kennedy in The Neuro-Image and Deleuze and Cinema, respectively, explicitly follow Deleuze, who is decidedly against phenomenology. However, I would argue that Deleuze, as well as Pisters, Kennedy, and other Deleuzian-inspired film theorists and film philosophers are closer to the phenomenological tradition of sensation and feeling than to the cognitive tradition of emotion and cognition

Steen Christiansen, PhD Associate Professor Department of Culture and Global Studies Aalborg University, Denmark steen@cgs.aau.dk 